\title{
Uzaktan Algılama Teknikleri ile Yanmış Alanların Tespiti: İmir Seferihisar Orman Yangını Örneği
}

\author{
Aslı Sabuncu ${ }^{1, *}{ }^{*}$, Haluk Özener ${ }^{1} \mathbb{D}$ \\ ${ }^{1}$ Boğaziçi Üniversitesi Kandilli Rasathanesi ve Deprem Araştırma Enstitüsü Jeodezi Anabilim Dalı Üsküdar 34684, İstanbul.

\section{Özet}

Çevreye verdiği zararlar nedeni ile orman yangınları dünyada doğal afetler içinde önemli bir yere sahiptir. Orman yangınları sadece ekosistemleri olumsuz etkilemekle kalmayıp, aynı zamanda ekonomik ve sosyal yașamda da ciddi sorunlara neden olmaktadır. Türkiye'de 1937-2016 yılları arasında meydana gelen orman yangınları sonucu 1.661.506 hektarlık orman alanı yanarak tahrip olmuștur. Orman yangınları sonrası araziden veri toplamak zaman zaman zor ve imkânsız olabilmektedir. Ayrıca yașanan afet sonrası arazi çalışmaları uzun süreceği ve maliyetinin fazla olacă̆ı göz önüne alınarak yanan alanların belirlenmesinde günümüzde uzaktan algılama teknolojilerine ve bu alanda kullanılan algoritmalarına sıklıkla başvurulmaktadır. Çeşitli özelliklere sahip farklı uydu görüntüleri (Landsat, MODIS, SPOT, vb.), yangın şiddetini, yangın hasarlarını ve yanmış bölgeleri haritalamak için son yillarda siklıkla kullanılan uzaktan algılama teknolojisinin önemli veri setleridir. Bu çalışmada 9 A ğustos 2009 tarihinde İzmir ili Seferihisar ilçesinde meydana gelen ve 4 gün süren orman yangını, Landsat 5 uydu görüntüleri kullanılarak uzaktan algılama teknikleri ile analiz edilmiştir. Çalışma bölgesine ait orman yangını öncesi Temmuz 2009 ve orman yangını sonrası Ağustos 2009 tarihli görüntüler alınarak Normalize Edilmiş Yanma Şiddeti (Normalized Burned Ratio-NBR) ve Normalize Edilmiş Vejetasyon İndeksi (Normalized Differenced Vegetation Index - NDVI) indeksleri ile bu indekslerin farkları kullanılarak elde edilen Fark Normalize Edilmiș Yanma Şiddeti (Difference Normalized Burned Ratio-Dnbr) ve Fark Normalize Edilmiş Vejetasyon İndeksleri kullanılarak yanarak tahrip olmuş alanlar tespit edilmiştir. Veri setine ayrıca piksel tabanlı kontrollü sinıflandırmanın maksimum benzerlik algoritması uygulanmıştır. Orman yangını sonrası yanarak tahrip olan alan dNDVI ile 711 ha, dNBR ile 695 ha, piksel tabanlı kontrollü sinıflandırma yönteminin maksimum benzerlik algoritması ile de 665 ha olarak hesaplanmıștır. Üç farklı yöntemin sonuçları Orman Genel Müdürlüğ̈̈ sonuçları ile uyumlu ve tutarlı olduğu sonucuna varılmıştır.

\section{Anahtar Sözcükler}

Piksel Tabanlı Sınıflandırma, İzmir-Seferihisar Orman Yangını, Uzaktan Algılama, NBR-dNBR, NDVI

\section{Detection of Burned Areas by Remote Sensing Techniques: İzmir Seferihisar Forest fire case study}

\begin{abstract}
The cause of damage to the environment, forest fires have a significant role in order to give way to natural disasters in the world. Forest fires not only affect ecosystems negatively, but also cause serious problems in economic and social life. As a result of forest fires that occurred between the years of 1937-2016 in Turkey 1,661,506 hectares of forest area was burnt. It is sometimes difficult and impossible to collect data from forests after forest fires. In addition, remote sensing techniques and algorithms are frequently used in determining the burning areas considering the long duration and the cost will be high. Different satellite images (Landsat, MODIS, SPOT, etc.) in various properties are important data sets of remote sensing technology which is frequently used in recent years to map fire intensity, fire damage and burnt zones. In this study, forest fire that occurred and continued 4 days in Seferihisar district of Izmir province on August 9, 2009 was analyzed by remote sensing techniques using Landsat 5 satellite images. Two Landsat images acquired in July 2009 as pre fire and in August 2009 as post-fire. In this study, the capacity of Normalized Burn Ratio (NBR) and Normalized Difference Vegetation Index (NDVI) indices and differenced Normalized Difference Vegetation Index (dNDVI) derived from Landsat 5 images have been analyzed in order to assess the fire severity. Besides NDVI and NBR indices results, maximum likelihood algorithm which is supervised classification method was applied to pre and post fire satellite images. The burnt area after forest fire was calculated as 711 ha with dNDVI, 695 ha with dNBR and 665 ha with maximum likelihood algorithm of pixel based supervised classification method. Based on the three different methods of results are compatible, rational and consistent with the results of the General Directorate of Forestry.
\end{abstract}

$\underline{\text { Keywords }}$

Pixel Based Image Analysis, Izmir-Seferihisar Forest Fire, Remote Sensing, NBR-dNBR, NDVI 


\section{Giriş}

Ormanlar, dünyadaki önemli ekosistemlerin başında yer almaktadır. En genel ve kapsamlı tanımı ile orman, ağaçlar ile bitki ve hayvan topluluklarının karşılıklı olarak etkileşimde bulunduğu bir ekosistemdir. Bu ekosistemde ayrıca, toprakta gözle görünmeyen organizmalar ile cansız çevrede karşılıklı bir denge içinde bulunmaktadır. Dünyada bilinçsiz kullanım, yangınlar vb. olaylar sonucu orman alanları tahrip olmakta ve alansal olarak azalmaktadır. Gerçekleştirilen son istatistiki verilere göre, yıllık olarak dünyada ormansızlaşma 13 milyon hektara (ha) ulaşmıştır (URL-1 2018). Ülkemizde ise orman ve ormanlık alanların toplamı 27 milyon ha olup bu rakamın ancak \% 1.6'sı koruma altındadır. Ayrıca Türkiye farklı bitki türleri açısından dünyanın en zengin ülkeleri arasında yer almaktadır. Tahmini olarak 10000'den fazla vasküler bitki Türkiye topraklarında yaşamaktadır ve bunların yaklaşık \%34'ü endemik tür olarak sınıflandırılmıştır (Özhatay ve Kültür 2006; Özhatay vd. 2009; Özhatay vd. 2011).

Bir yangının başlaması ve sürmesi için üç farklı parametreye ihtiyacı vardır. Bu parametreler; 1sı, yakıt ve oksijendir (Şekil 1). Bu parametrelerden herhangi biri yangın üçgeninde yer almadığı takdirde yangın olayı gerçekleşmez. Orman yangınlarının başlaması için ise belli bazı parametrelerin olması gerekir. Yangının tutuşması ve yayılması, yakıı nemi, hava koşulları, yakıtın türü ile topoğrafya yangının başlaması için önemli rol oynamaktadır. Yakıt nemi ve bölgenin hava koşulları orman yangını tehlikesinin zamansal ve kısa süreli değişimi ile ilişkili iken, yakıtın türü ve topografya ise mekansal ve uzun süreli değişim ile ilişkilidir.

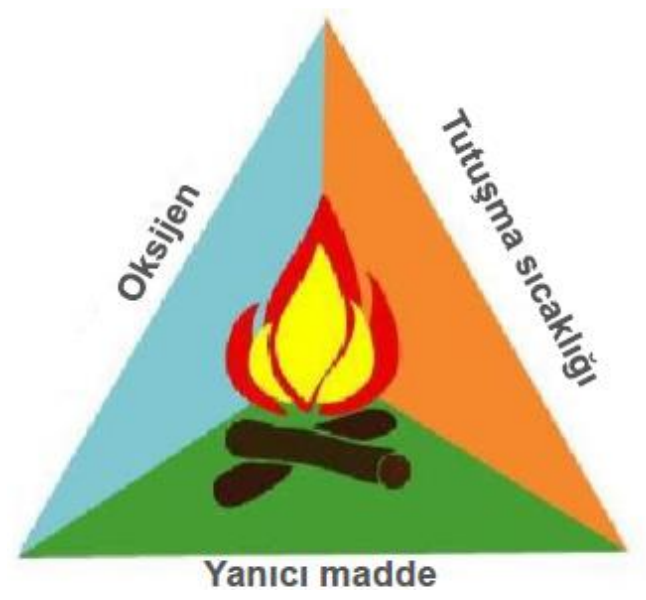

Şekil 1: Yangın üçgeni (URL-2 2018)

Ayrıca, orman yangınları, küresel ölçekte ele alındığında sadece iklim değişikliğinde değil aynı zamanda toprak verimliliği ve yapısı üzerinde de olumsuz etkileri bulunmaktadır (Vieria vd. 2011). Orman yangınları sonrası değişen toprak koşulları yağmurun zemine olan etkisini değiştirmektedir. Yanmış olan ağaç ve bitkilere ait küller zeminde geçirimsiz bir tabaka oluşturmaktadır. Meydana gelen tabaka infiltrasyonu azaltmakta ve yağış sonrası yağmurun derinlere sızmasını önlemektedir. Bunun sonucu toprak-su dengesi bozularak erozyonu tetiklemektedir (Robichaud 2000; Rulli ve Rosso 2007). Yangın esnasında zemin sıcaklığının değişmesi de olumsuz birçok sorunu beraberinde getirmektedir. Yangın sırasında zemindeki sıcaklık artışı maksimum 200-300 ${ }^{\circ} \mathrm{C}$ arasında değişmekte ve bu sıcaklıkta toprağı bir arada tutan bütün organik maddeler ölmektedir. Proteinler ve bitki dokuları 40-70 ${ }^{\circ} \mathrm{C}$ 'de ölürken, bitki kökleri ve tohumlar $70-90^{\circ} \mathrm{C}$ 'de ölür. Yangın sırasındaki aşırı sıcaklık artışı sonucu bitkilerin toprak üstü kısımlarının ortadan kalkması sonucu toprak güneş 1şınlarına daha fazla maruz kalmaktadır. Yanmış olan organik maddelerden dolayı meydana gelen koyu renk yüzeyde daha fazla güneş ışınını çekerek zeminin daha fazla ısınmasına neden olmaktadır. Bunun sonucu olarak fidanlar kurumakta, organik maddeler ile besinler ölmekte ve topraktaki su dengesi bozulmaktadır (Neary vd. 1999; Y1ldız vd. 2010).

Akdeniz havzası, her yıl orman yangınlarına maruz kalan ve bu orman yangınlarına uyum sağlamış ekosisteme sahip bütünleşik bir bölgedir. Akdeniz bölgesinde meydana gelen orman yangınlarında son yıllarda önemli artışlar gözlenmiştir. Özellikle bu bölgede meydana gelen orman yangınları, 1970'li yıllarda meydana gelen yangınların iki katıdır. Ayrıca orman yangınları ile ilgili istatistikler incelendiğinde Akdeniz havzasında yanan orman alanı yıllık bazda 600.000 ha kadar çıktığı gözlenmiştir (Rulli ve Rosso 2007).

Ülkemiz yangın riskinin çok yüksek olduğu Akdeniz havzasında yer almakta ve sürekli yangın riski altında bulunmaktadır. Son yıllarda gerçekleştirilmiş olan orman istatistiki çalışmalarına göre Türkiye'nin orman varlığ 22.3 milyon ha olup, bu ormanlık alanların \%35'i birinci, \%23'ü ikinci, \%22'si üçüncü, \%15'i dördüncü ve \%5'i ise beşinci derecede yangına hassas bölgelerde yer almaktadır (Küçük ve Ünal 2005). Türkiye'de, Akdeniz ve Ege bölgeleri boyunca Hatay'dan başlayıp İstanbul'a kadar uzanan sahil şeridi en yüksek yangın riskine sahip bölgeler olarak belirlenmiştir. Bir başka deyişle, Türkiye'nin orman alanının yaklaşık \%57'si (12.5 milyon ha) yangına duyarlı alanlarda bulunmaktadır. 
Bilgili ve Küçük (2001) yaptıkları çalışmada orman alanlarını yangın hassasiyetine göre sınıflandırmıştır. Bölgelerin orman yangını sonrası hassasiyetlerini gösteren derecelendirme Tablo 1'de verilmiştir.

Tablo 1: Ormanların yangınlara hassasiyet derecelerine göre yapılan sınıflandırma (Bilgili ve Küçük 2001)

\begin{tabular}{|c|c|c|}
\hline Tehlike Sınıfı & Açıklama & Yıllık ortalama yangın adedi \\
\hline I & En hassas & 10.1 ve daha fazla \\
\hline II & Çok hassas & $6.1-10.0$ \\
\hline III & Orta hassas & $3.1-6.0$ \\
\hline IV & Az hassas & $1.1-3.0$ \\
\hline V & En az hassas & 1.0 ve daha az \\
\hline
\end{tabular}

1937-2016 yılları arasında ülkemizde meydana gelen orman yangınları sonucu toplamda 1.661.506 ha ormanlık alan zarar görmüştür. Türkiye'de meydana gelen orman yangınlarının çıkış sebepleri ve oranları incelendiğinde \% 59'u ihmal ve dikkatsizlik, \%20'si nedeni bilinmeyen, \%12'si kasıt (kundaklama, yer açma, terör), \%9'u doğal nedenler (yıldırım düşmesi vb.) olmaktadır.

Orman yangınları sonrası, araziden veri toplamak genellikle yanan alanlara ulaşılmasının zor veya imkânsız olması ve arazi çalışmalarının maliyetinin yüksek olması nedeni ile yapılamamaktadır. Bu kısıtlamalar nedeni ile son yıllarda orman yangını sonrası çalışmalar için uzaktan algılama teknolojilerine başvurulmaktadır. Çok yönlü veri toplama ve sinoptik görüntüleme özelliği, uzaktan algılama uyduları ile mümkündür (Algancı vd. 2011). Yangın yönetiminin farklı aşamalarında risk tahmini, tespiti ve değerlendirmesi için de yine uzaktan algılama teknolojilerine başvurulmaktadır.

Orman yangınları ile mücadelede hem ulusal hem de uluslararası kapsamda yapılan çalışmalar son 50 yılda büyük bir ivme kazanmıştır. Başta ABD, Kanada, Avusturalya ve Akdeniz ülkeleri olmak üzere dünyanın birçok ülkesinde orman yangınları ile ilgili çalışmalar yapılmaktadır (Kane vd. 2015; Abatzoglou ve Williams 2016; Chuvieco vd. 2012; Barbero vd. 2015; Schelhaas vd. 2015; Lopez vd. 2007; Sanjuan vd. 2014; Perry vd. 2014; Doherty vd. 2017; Mölders 2010; Joseph vd. 2009; Dowdy vd. 2009).

Uzaktan algılama teknolojilerinde yaşanan hızlı gelişmeler sayesinde uydu verilerinin çeşitlenmesi ile orman yangını sonrası yanarak tahrip olan alanların tespit edilmesi daha etkili ve hızlı olmaktadır. Uydu verilerine uygulanmakta olan farklı sınıflandırma teknikleri ile (Piksel veya obje tabanlı) yanmış alanların tespit edilmesine yönelik birçok çalışma günümüzde literatürde yer almaktadır (Koutsias ve Karteris 2000; Rogan ve Franklin 2001; Li vd. 2003 ; Dragozi vd. 2014; Chen vd. 2016; Kavzoglu vd. 2016). Ülkemiz ise orman yangınları ile ilgili çalışmalara ancak 1990'lı yılların sonralarında başlamıştır (Göktepe ve Avc1 2015; Küçükosmanoğlu vd. 2015; Türkeş ve Altan 2014; Avc1 ve Boz 2017; Atmış ve Günşen 2016). Ayrıca orman yangınları ile ilgili son yıllarda birçok yüksek lisans veya doktora tez çalışmasına da rastlamak mümkündür (Esemen 2011; Çekmek 2018; Hacısalihoğlu 2018; İnan 2018; Tonbul 2015).

\section{2. Çalışma Alanı}

Çalışma alanı, Ege bölgesinde yer alan, İzmir ili güneybatısında bulunan Seferihisar ilçesidir. İlçe, kuzeybatı ve kuzeyde

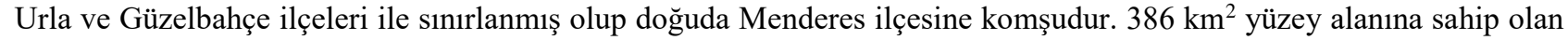
Seferihisar ilçesi, denizden 30 m yükseklikte yer almaktadır (URL-3 2018). Çalışma bölgesi 26 45' $00^{\prime \prime} \mathrm{D}$ ile $27^{\circ} 01^{\prime} 00$ "D boylamları ile $38^{\circ} 17^{\prime} 00^{\prime \prime} \mathrm{K}$ ile $38^{\circ} 02^{\prime} 0^{\prime \prime} \mathrm{K}$ enlemleri arasında yer almaktadır (Şekil 2). İklim özellikleri açısından Akdeniz makro ikliminde yer alan Seferihisar ilçesinin yıllık ortalama sıcaklığ $17^{\circ} \mathrm{C}$ olup, Ocak ayında ortalama sıcaklık $8^{\circ} \mathrm{C}$, Temmuz ayında $27^{\circ} \mathrm{C}$ 'dir (Gülersoy 2014). Ayrıca Akdeniz makro ikliminde yer alması sebebi ile yılın 4 ayı (Haziran, Temmuz, Ağustos, Eylül) bölgede sicaklıklar $20^{\circ} \mathrm{C}$ 'nin üstünde seyretmektedir. Seferihisar ilçesinde yıllık ortalama yağış miktarı $588.1 \mathrm{~mm}$ 'dir. En fazla yağış kış mevsiminde (Aralık=145 mm) gerçekleşirken, en az yağış yaz mevsiminde (Ağustos=1 mm) gerçekleşmektedir (URL-4 2018). İlçenin bitki örtüsü maki topluluğu ve orman topluluğudur. Bölgedeki toplam orman alanı $132.400 \mathrm{~m}^{2}$ olup ormanlık alanlar ilçenin kıyıdan iç kısımlarına doğru yoğunlaşmaktadır. Bölgedeki yıllık ortalama rüzgar hızı $12.6 \mathrm{~km} / \mathrm{s}$ nispi nem oranı ise \%64 olarak tespit edilmiştir (Alganc1 vd. 2010). 


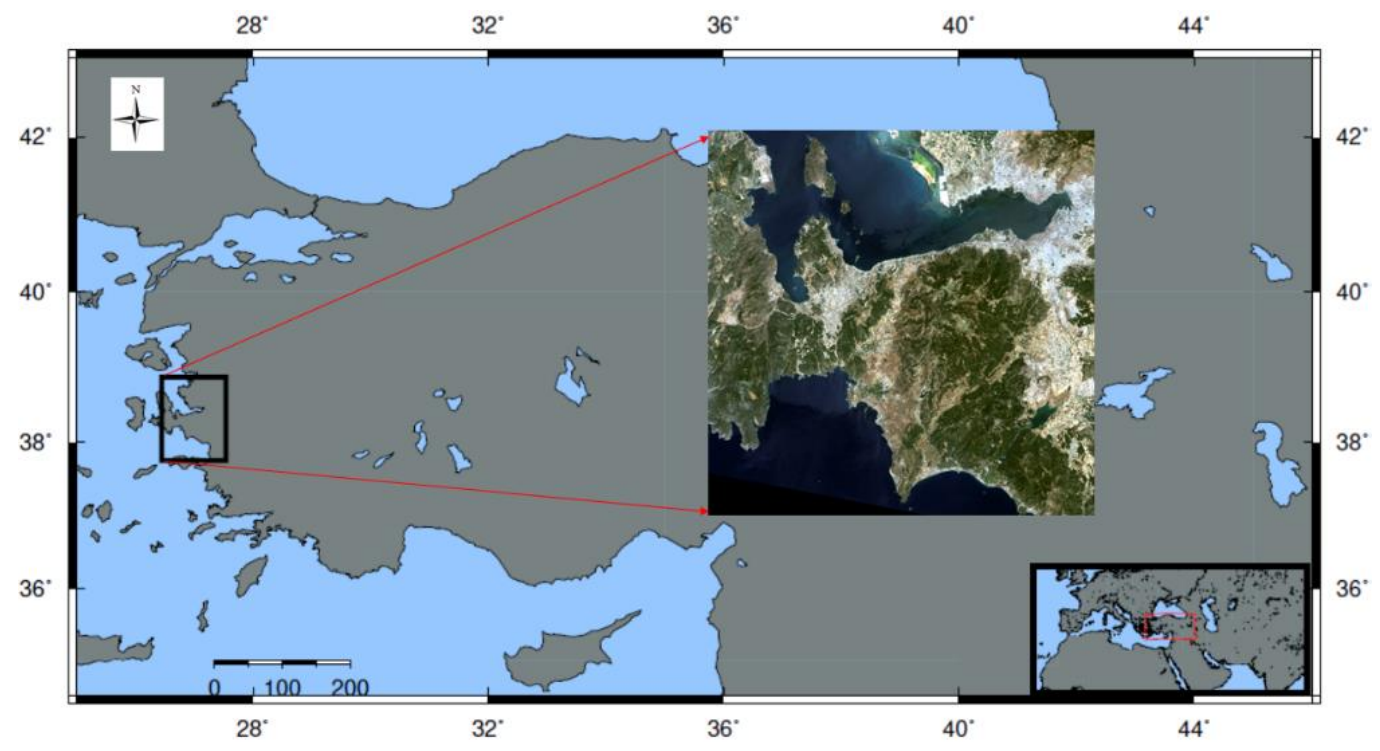

Şekil 2: Çalışma alanının haritası ve Landsat 5 görüntüsü

\section{Veri Seti}

Bu çalışmada İzmir ili Seferihisar ilçesinde 9 Ağustos 2009 tarihinde başlayan orman yangını ele alınarak uydu görüntüleri ile yangın sonrası hasar tespit çalışması yapılmıştır. Orman Genel Müdürlüğünün yangın sonrası yapmış olduğu hasar tahmin çalışmalarının sonuçlarına göre 700 ha ormanlık alan tahrip olmuştur. Bölgede meydana gelen yangın sonrası tahrip olan alanı tespit etmek için orta çözünürlüklü uydu görüntüleri kullanılmıştır. Uydu görüntüleri, United States Geological Survey (USGS) web sayfasından ücretsiz olarak temin edilmiştir. Landsat uydu verileri, orman yangınının etkilerini değerlendirmek için önemli veri setlerinin başında yer almaktadır. Yedi (7) adet spektral banda sahip olan Landsat 5 uydusunun, 30 m’lik çözünürlüğü orman yangınlarını tespit etmek için yeterli bir çözünürlük olarak görülmektedir (URL-5 2018). Ayrıca yangından hemen önce ve hemen sonraki 16 günlük zamansal çözünürlük yanan alanların yeşillenmeden tespiti için iyi bir fırsat sunmaktadır. Çünkü orman yangının başlama tarihi 9 Ağustos 2009 olup yangın öncesine ait 26 Temmuz 2009 ve yangın sonrasına 14 Ağustos 2009 tarihlerine ait uydu görüntüleri mevcuttur. Şekil 3'te çalışma alanının uydu görüntüleri sunulmaktadır. Ayrıca Tablo 2'de kullanılan uydu görüntülerinin özelliklerine yer verilmiştir.

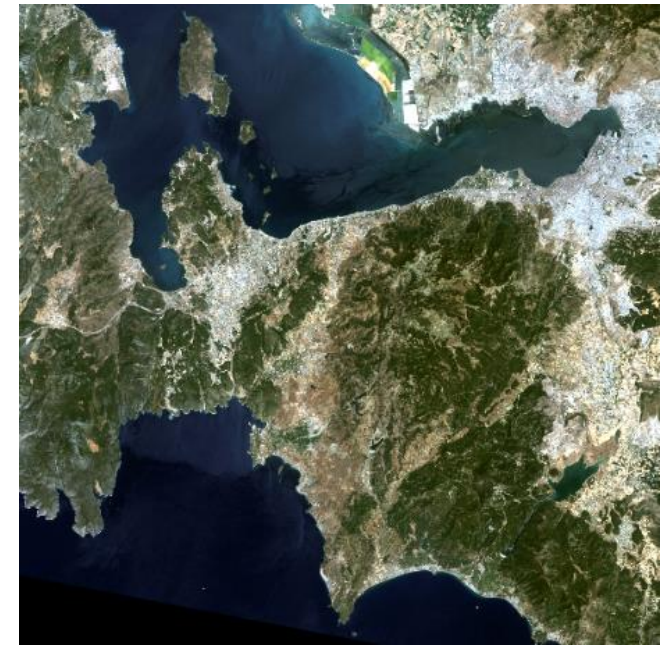

(a)

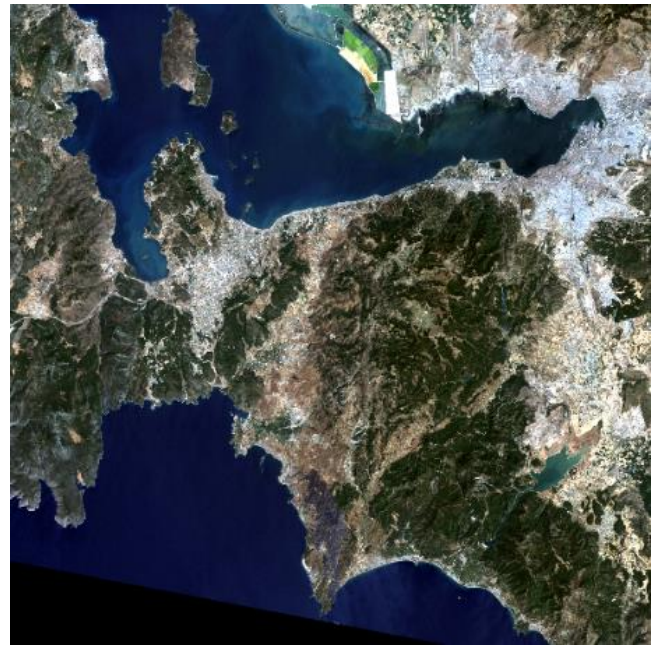

(b)

Şekil 3: Çalışma alanı Izmir - Seferihisar a) Yangın öncesi Landsat 5 uydu görüntüsü b) Yangın sonrası Landsat 5 uydu görüntüsü 
Tablo 2: Uygulamada kullanılan veri setinin özellikleri

\begin{tabular}{|c|l|c|c|}
\hline Veri Seti & \multicolumn{1}{|c|}{ Bantlar } & $\begin{array}{c}\text { Dalga Boyu } \\
\text { (mikrometre) }\end{array}$ & Çözünürlük \\
\hline \multirow{4}{*}{$\begin{array}{c}\text { Landsat 5 } \\
\text { TM }\end{array}$} & Bant 1- Mavi & $0.45-0.52$ & $30 \mathrm{~m}$ \\
\cline { 2 - 4 } & Bant 2- Yeşil & $0.52-0.60$ & $30 \mathrm{~m}$ \\
\cline { 2 - 4 } & Bant 3- KIrmız1 & $0.63-0.69$ & $30 \mathrm{~m}$ \\
\cline { 2 - 4 } & Bant 4- NIR & $0.76-0.90$ & $30 \mathrm{~m}$ \\
\cline { 2 - 4 } & Bant 5 -SWIR 1 & $1.55-1.75$ & $30 \mathrm{~m}$ \\
\cline { 2 - 4 } & Bant 6 -Termal & $10.40-12.50$ & $120 * 30 \mathrm{~m}$ \\
\cline { 2 - 4 } & Bant 7- SWIR 2 & $2.08-2.35$ & $30 \mathrm{~m}$ \\
\hline
\end{tabular}

120* 30: TM Band 6, 120 metre çözünürlükte veri almış olup 30 metreye yeniden örneklendi.

\section{Kullanılan Yöntemler}

9 Ağustos 2009 tarihinde İzmir ili Seferihisar ilçesinde meydana gelen orman yangını sonucunun değerlendirildiği bu çalışmada, uydu görüntülerine çeşitli uzaktan algılama indeksleri (NBR, dNBR, NDVI) ile yanan alanın miktarının tespitine yönelik piksel tabanlı kontrollü sınıflandırma tekniği uydu verilerine uygulanmıştır. Çalışma, verilerin temini, ön işleme, bitki örtüsü ve yanan alan endekslerinin hesaplanması, piksel tabanlı kontrollü sınıflandırma ve doğruluk analizi olmak üzere toplamda beş ana bölümden oluşmaktadır (Şekil 4). Uydu görüntülerine gerçekleştirilen her işlem ENVI 4.8 yazılımı kullanılarak gerçekleştirilmiştir. Sınıflandırma sonrası, bütün elde edilen sonuçlar OGM'den alınan hasar tahmin sonuçları ile karşılaştırılmıştır.

Veri setinin temini Landsat 5 TM

\begin{tabular}{|l|l|}
\hline \multicolumn{2}{|c|}{ Landsat 5 TM } \\
\hline \multicolumn{2}{|c|}{ Önişleme } \\
\hline Bantların birleştirilmesi & Tanımlı sınırlar tarafından kesilmesi \\
\hline \multicolumn{2}{|c|}{ Değişim Saptama Analizi } \\
\hline NDVI, NBR indekslerinin oluşturulması & Piksel tabanlı kontrollü sınıflandırma işlemi \\
\hline
\end{tabular}

Doğruluk analizi ve tüm sonuçların karşılaştırılması

\section{Şekil 4: Uygulama sırasında izlenen işlem adımları}

\subsection{Normalize Edilmiş Bitki Örtüsü İndeksi (Normalized Difference Vegetation Index- NDVI)}

Yeşil bitki örtüsü, yapraklarında bulunan klorofil maddesini kullanarak fotosentez işlemini gerçekleştirir. Fotosentez sırasında güneşten gelen elektromanyetik enerjinin $0.63 \mu \mathrm{m}-0.69 \mu \mathrm{m}$ dalga boyu aralığında olan ve kırmızı 1şığa karşılık gelen kısmı kullanılır. Bu sebeple, kırmızı ışığın yansımasını ölçen bir uydu görüntüsü, canlı bitki örtüsünün yoğun olduğu alanlarda düşük sayısal değerlere sahip olacaktır (Kandemir 2010). Uzaktan Algılama uygulamalarında yeşil bitki örtüsünün tespitinde, zaman içinde pozitif ve negatif yönde değişimimin izlenmesinde en sık kullanılan indeks NDVI indeksidir. NDVI, yakın kızıl ötesi ve kırmızı bant görüntülerinin matematiksel bir oranla ifade edilmesidir (Formül 1). Yakın kızıl ötesi dalga boyu $(0.68-0.78 \mu \mathrm{m})$, kırmızı dalga boyu $(0.61-0.68 \mu \mathrm{m})$, NDVI (birimsiz) ise vejetasyon indeks değerini temsil etmektedir (Tucker 1979). NDVI, [-1 ile +1] arasında değişen aralıkta ifade edilmektedir. Vejetasyonun yoğun olduğu bölgelerde NDVI + 1'e yaklaşırken, bitki örtüsünün seyrekleşmesi ve çıplak toprakta NDVI değeri +1'den uzaklaşmakta ve sıfıra yaklaşmaktadır. Bulut, su ve kar gibi farklı nesnelerin NDVI indeks değerleri ise -1 'e yakındır (Hatfield vd. 1985).

$$
N D V I=\frac{N I R-B a n t 3}{N I R+B a n t 3}
$$

Yangın öncesi ve sonrası görüntüler için ayrı ayrı NDVI dönüşümü hesaplandığında, yangın sonrası NDVI görüntüsünde, bitki örtüsü haricindeki alanlar ile birlikte yanan alan da siyah gözükmektedir (Şekil 5b). Yangın öncesi görüntülerde yoğun ve sık orman alanları için NDVI değerleri +1 'e yaklaşmaktadır. Aynı şekilde yangın sonrası görüntülerde yanarak tahrip olmuş orman alanlarının NDVI değerlerinin -1'e yaklaştığ 1 gözlenmiştir. Bu nedenle, yangın öncesi görüntüler için NDVI eşik değeri pozitif değerler alınırken yangın sonrası aynı bölgenin NDVI eşik değeri negatif değerler alınarak filtreleme gerçekleştirilmiştir. 


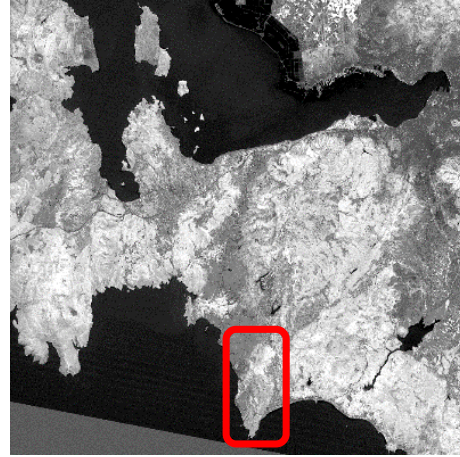

(a)

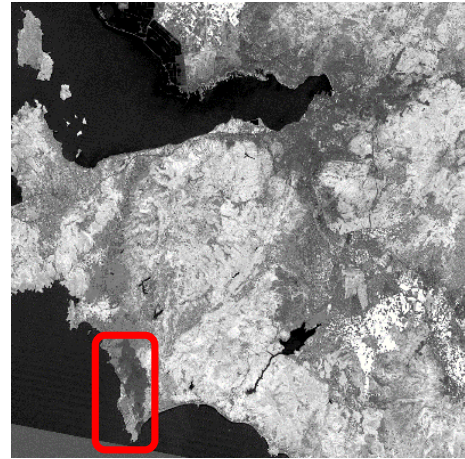

(b)

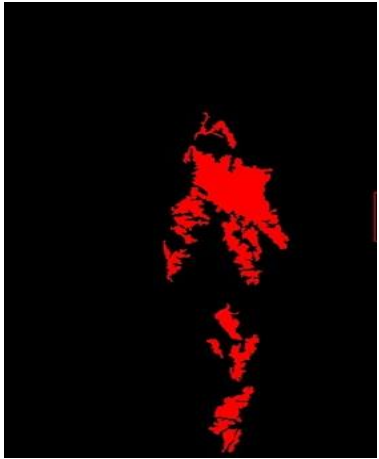

(c)

Şekil 5: NDVI dönüşümü a) Yangın öncesi b) Yangın sonrası c) Yangın öncesi ve yangın sonrası değişim saptama analizi sonucu

Bölgede meydana gelen orman yangını sonrası, yangın öncesi ve yangın sonrası NDVI değerleri hesaplanarak, bu değerlerdeki değişim için değişim saptama analizi yapılmıştır. Değişim saptama analizi sonuçları incelendiğinde, yangın sonucu tahrip olan yeşil alan 7909 piksel olarak bulunmuştur. Bu piksellerin alansal karşılığı ise 711 hektardır (Şekil 5c). OGM'den yangın sonrası yapmış olduğu hasar tespit çalışmasında 700 ha'lık orman alanının yanarak hasar gördüğü tespit edilmiştir. Bu sebeple NDVI Değişim saptama analizi sonucu ile OGM'nin hasar tespit sonucu birbirine yakın ve tutarlıdır (URL-6 2018).

\subsection{Normalize Edilmiş Yanma Şiddeti (NBR) ve Fark Normalize Edilmiş Yanma Şiddeti (dNBR)}

Orman yangınları sonrası, bitki örtüsünde fiziksel özelliklerin dışında kimyasal değişiklikler de meydana gelmektedir. Bitki örtüsünde terlemenin azalması, yüzeyin kül ile kaplanması ve yüzey sıcaklığındaki ani artış sonucu spektral yansıtımlarda önemli değişiklikler gözlenmektedir (Lanorte 2013). Orman yangınları sonrası bölgede meydana gelen ani vejetasyon değişikliği için NDVI dışında, yanan bölgelerin tespitinde, uydu görüntüleri ile oluşturulmuş olan spektral indeksler aktif olarak kullanılmaktadır. Normalize Edilmiş Yanma Şiddeti İndisi (NBR) orman yangınlarının tespitinde literatürde sıklıkla kullanıldığı görülmektedir. Bu indeks özellikle ormanlık alanlardaki yangın öncesi ve yangın sonrası görüntüler arasındaki değişikliği tespit edebilmek için 7.bant ile 4.bantın matematiksel bir oranla ifade edilmesidir (Formül 2) (Key ve Benson 2005a; Miller ve Yool 2002). 4. bant, canlı bitki örtüsünün klorofil içeriğine duyarlı olan kızıl ötesi 0.76-0.90 $\mu \mathrm{m}$ dalga boylarını kapsarken, 7 bant ise hem topraktaki hem de bitki örtüsündeki su içeriğine, fotosentetik olmayan bitki örtüsünün içeriğine, kil, mika ve bazı oksitler ve sülfatlar gibi sulu minerallere karşı hassas olup bu maddeleri çıkarmaktadır. Ayrıca, 7.bantın dalga boylarının, odun dışı ortamdaki (ölü) odun toprak, kül ve kömürleşmiş odunlardan bir yangın sonrası ortamda ayrılmasında hassas olduğu görülmüştür (Jia vd. 2006). NBR, bu iki bantın kullanılması sonucunda, canlı bitki örtüsü, nem içeriği ve yangından sonra meydana gelebilecek bazı toprak koşullarındaki değişimlere özellikle duyarlıdır. Bu sebeple yanmış yeşil alanların tespitinde Normalize edilmiş yanma şiddeti (NBR) indeksi kullanılmaktadır. Normalize edilmiş yanma şiddeti indisi (NBR) yakın kızılötesi (NIR) ve kısa dalga kızılötesi (SWIR) bantları kullanılarak elde edilen matematiksel formüller ile ifade edilmektedir (Roy vd. 2006, Veraverbeke vd. 2010).

$$
N B R=\frac{(N I R-S W I R)}{(N I R+S W I R)}
$$

Günümüzde, en yaygın olarak kullanılan orman yanma şiddeti haritasını tespit etmek için Miller vd. (2007), yaptıkları çalışma ile Differenced Normalized Burn Ratio (dNBR) metodunu geliştirerek, vejetasyonda meydana gelen zararın boyutlarını sınıflandırmışlardır. Fark Normalize Yanma Şiddeti (Differenced Normalized Burn Ratio- dNBR), orman yangını öncesi ve sonrası normalize edilmiş yanma şiddeti indekslerinin birbirinden çıkarımı sonucu elde edilmektedir (Formül 3). Ayrıca, dNBR indisi ile karbon salınımı, aerosol üretimi ve biyokütle parametrelerindeki değişiklikler hesaplanarak yanma şiddeti belirlenmektedir (Miller ve Thode 2007).

$$
\Delta \mathrm{NBR}=\mathrm{NBR}_{\text {Yangın öncesi }}-\mathrm{NBR}_{\text {Yangın sonrası }}
$$

Teorik olarak Fark Normalize Yanma Şiddeti indisi incelendiğinde aldığı değerlerin -2.00 ile +2.00 arasında olduğu gözlenmiştir. Bu değerlerden yanmış alanlar için değerler 0.10 ile 1.35 arasında değişirken, yanmamış alanlar -0.10 ile +0.10 arasında değişmektedir Ayrıca yangın sonrası ileri derecede yeniden büyüme gösteren bitki örtüsü için ise - 0.50 ile -0.10 arasında değerler aldığı gözlenmiştir (Key ve Benson 2006) (Tablo 3) . 
Tablo 3: Yanma şiddeti kategorileri (USGS-FIREMON)

\begin{tabular}{|c|c|}
\hline dNBR & Yanma Şiddeti \\
\hline$<-0.25$ & Yüksek yangın sonrası yeşerme \\
\hline$-0.25 /-0.1$ & Düşük yangın sonrası yeşerme \\
\hline$-0.1 / 0.1$ & Yanmamış \\
\hline 0.10 .27 & Düşük Yanma şiddeti \\
\hline $0.27 / 0.44$ & Orta/düşük yanma şiddeti \\
\hline $0.44 / 0.66$ & Orta/Yüksek yanma şiddeti \\
\hline$>0.66$ & Yüksek yanma şiddeti \\
\hline
\end{tabular}

Çalışma bölgesinde meydana gelen yangın sonrası temin edilen Landsat 5 uydu görüntülerine NBR indeksi uygulanmış ve daha sonra orman yangını öncesi ve sonrası görüntüleri birbirinden çıkartılmıştır. Şekil 6'da sırası ile orman yangını öncesi bölgeye ait veri setine uygulanan NBR, orman yangını sonrası bölgeye ait veri setine uygulanan NBR ve dNBR sonucu yer almaktadır. Yangın sonrası NBR uygulanan veri setinde görüldüğü üzere yanan alanlar siyah olarak gözükmektedir (Şekil 6b). Fark Normalize Yanma Şiddeti indeksinin sonuçları incelendiğinde ise yanarak tahrip olmuş alan 695 ha olarak hesaplanmıştır.

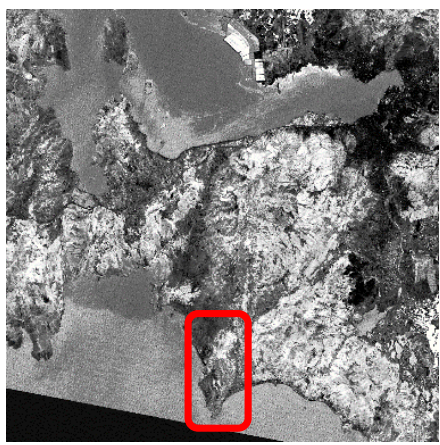

(a)

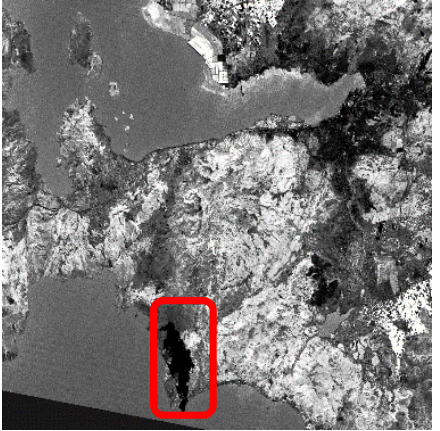

(b)

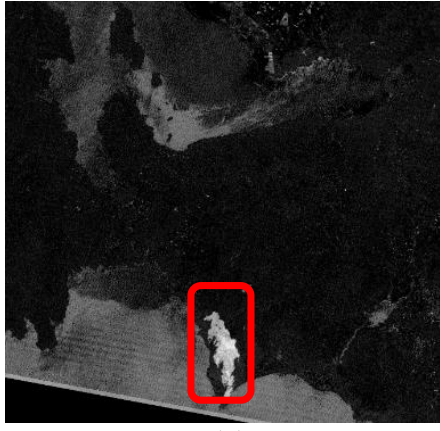

(c)

Şekil 6: NBR indeksi uygulaması a) Yangın öncesi b) Yangın sonrası c) Yangın öncesi ve yangın sonrası fark NBR.

\subsection{Piksel Tabanlı Kontrollü Sınıflandırma}

Piksel tabanlı sınıflandırma, klasik sınıflandırma tekniği olarak bilinmekte ve her bir pikselin tek bir arazi örtüsü sınıfına karşılık gelecek şekilde sınıflandırılması amaçlanmaktadır. Görüntüdeki piksellerin sahip olduğu spektral değerler, piksel tabanlı sınıflandırma işleminin temel veri setini oluşturur. Literatürde piksel tabanlı sınıflandırma yöntemleri için Maksimum Benzerlik, Maksimum Komşuluk vb. farklı algoritmalar kullanılmaktadır. Maksimum Benzerlik algoritması piksel tabanlı sınıflandırma içinde en sıklıkla kullanılan yöntemdir. Bu yöntemde istatistiksel değerler olan ortalama değer, varyans ve kovaryans vb. dikkate alınır. Maksimum Benzerlik sınıflandırma yönteminde sınıflar için eş olasılık eğrileri tanımlanarak sınıflandırılacak pikseller üyelik olasılı̆̆ı en yüksek olana atanır. Ayrıca bu yöntemde piksellerin, sadece parlaklık değerleri değil, aynı zamanda her sınıf için ayrım oluşturacak varyans-kovaryans matrisi oluşturulur (Sabuncu 2018).

NDVI ve NBR indekslerinin yanı sıra, uydu görüntülerini sınıflandırmak için orta konumsal çözünürlüklü uydu verilerine bilimsel çalışmalarda da sıklıkla başvurulan yöntem olan piksel tabanlı kontrollü sınıflandırma yöntemi kullanılmıştır. Orman yangını öncesi ve sonrası görüntülerde, 432 (RGB) Landsat bantları kullanılarak yanlış renk bileşimi elde edilmiş ve bitki örtüsü sınıflandırmasında, sağlıklı bitki örtüsünü gösteren ve kızılötesi 1şığı güçlü bir şekilde yansıtan bant sıralaması seçilmiştir. Daha sonraki aşama ise 6 kontrol bölgesi (deniz/göl, yeşil alan, yanmış alan, şehir, tarım alanı, çıplak toprak) üretmek üzere sınıflara ait kontrol bölgeleri homojen olarak seçilmiştir. Her bir pikselin bir sınıfa ait olma olasılığına dayanan Maksimum Benzerlik Algoritması kullanılarak, 6 sınıf üretilmiştir (Şekil 7a/b). Tamamlanan analiz sonucunda ise 665 ha ormanlık alanın tahrip olduğu belirlenmiştir.

Sınıflandırma sonrası doğruluk analizi, seçilen referans veriler ile sınıflandırılmış görüntü arasındaki uyuşumun belirlenmesi amacıyla yapılır. Bu amaca yönelik olarak test bölgelerinde her bir sınıfa ait belirli sayıda referans pikselleri seçilmiştir. Orman yangını sonrası Maksimum Benzerlik yöntemi sonucunda elde edilen piksel-tabanlı sınıflandırma doğruluk analizi klasik hata matrisi ile irdelenmiştir. Doğruluk analizinde, her bir sınıf doğruluğunun ortalama değeri olan "Genel Doğruluk (GD; yüzde olarak)" ile sınıflandırma doğruluğunu ağırlıklı olarak hesaplayan bir istatistiksel ölçüt olan "Kappa Katsayısı (KK)" kullanılmıştır. Maksimum Benzerlik yöntemi ile sınıflandırma sonucu GD: 76.66\% ve KK değeri ise 0.71 olarak elde edilmiştir. Yanmış orman alanının üretici doğruluğu $80.54 \%$ iken, kullanıcı doğruluğu $72.77 \%$ olarak elde edilmiştir. 


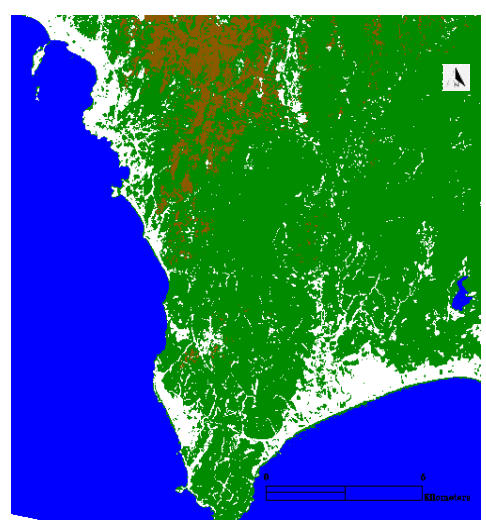

(a)

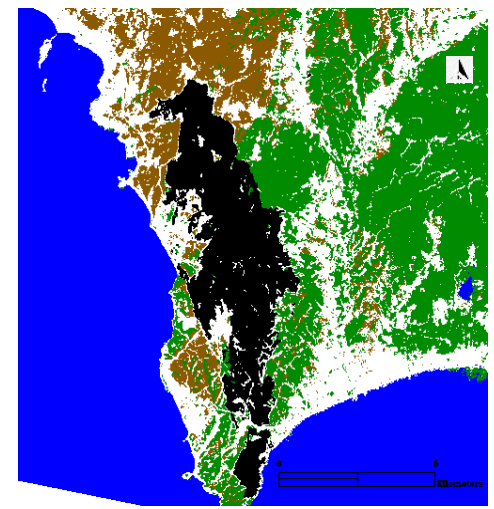

(b)

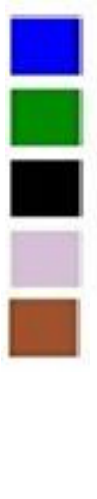

Deniz/Göl

Yeşil alan

Yanmış alan

Şehir/Yol

Toprak/Tarım

(c)

Şekil 7: Kontrollü sınıflandırma a) Yangın öncesi b) Yangın sonrası c) Sınıflar

\section{Sonuçlar}

Dünyanın en büyük doğal zenginlik kaynağı ormanlar olup, doğal dengenin sağlanmasında hayati öneme sahip olmalarının yanı sıra ekolojik ve çevresel faydalar sağlamaları açısından itibarıyla iyi korunmalıdırlar. Tüm Dünya'da olduğu gibi ülkemizde de ormanlara verilen zararların başında orman yangınları gelmektedir. Özellikle orman yangınları çıkması için en uygun şartlara sahip olan Akdeniz bölgesinde, bu doğal tehdite karşı her an tetikte olunmalı ve gerekli önlemler alınarak yangın yönetimi ve yangın hasar tespiti belirleme işlemleri sistematik bir şekilde yapılmalıdır.

Bu çalışmada, 9 Ağustos 2009 tarihinde İzmir ili Seferihisar ilçesinde meydana gelmiş olan orman yangını sonucunda yanan alanı Landsat 5 uydu görüntüleri üzerinden tespit etmek ve haritalamasını yapmak için 3 farklı uzaktan algılama analiz yöntemi kullanılmıştır. Bu yöntemler sırası ile NBR- dNBR, NDVI-NDVI Değişim saptama analizi, piksel tabanlı kontrollü sınıflandırmadır. Yanarak tahrip olmuş olan ormanlık alanlar NBR-dNBR ile 695 ha, NDVI-NDVI Değişim saptama analizi ile 711 ha, piksel tabanlı kontrollü sınıflandırma yöntemi ile de 665 ha bulunmuştur. İzmir orman bölge müdürlüğünün yangın sonrası bölgede yapmış olduğu hasar tespit çalışmaları sonucu yaklaşık 700 ha ormanlık alan tahrip olduğu belirlenmiş ve bu yüzden uzaktan algılama analiz sonuçları ile tutarlı olduğu sonucuna varılmıştır.

Uzaktan algılama teknolojisi son yıllarda uydu teknolojilerinde yaşanan önemli gelişmeler sayesinde çok farklı disiplinlerin çalışma konularını da kapsayacak araştırma konuları bulunmaktadır. Bu doğrultuda özellikle kısa süreli ve hızlı değişimler için (örneğin orman yangını) uzaktan algılama teknolojilerinin sıklıkla kullandığı NDVI ve NBR indeksleri ile piksel tabanlı kontrollü sınıflandırma algoritmasına başvurulması gerekliliği hem zaman hem de maddi açıdan fayda sağlamakta ve elde edilen sonuçların OGM sonuçları ile tutarlı olması ve özellikle yangın sonrası değerlendirmelerde uzaktan algılama yöntemlerinin başarısını vurgulamaktadır.

\section{Kaynaklar}

Abatzoglou John T., Williams A.P., (2016), Impact of Anthropogenic Climate Change on Wildfire Across Western us Forests, Proceedings of the National Academy of Sciences, 113, $11770-11775$.

Alganc1 U., Sertel E., Ormeci C., (2010), Forest Fire Damage Estimation Using Remote Sensing and GIS, 30th EARSeL Symposium Remote Sensing for Science, Education, and Natural and Cultural Heritage UNESCO, 31 May - 3 June, Paris, France.

Atmış E., Günşen H.B., (2016), Kentleşmenin Türkiye Ormancılığının Dönüşümüne Etkisi (1990-2010 Dönemi), Journal of the Faculty of Forestry Istanbul University, 66 (1), 16-29.

Avcı M., Boz K., (2017), Mersin-Gülnar Ormanlarında Yangın Sorunu, Yangınların Dağılımı ve Büyük Yangınların Değerlendirilmesi, Türkiye Ormanc1lık Dergisi, 18(2), $160-170$.

Barbero R., Abatzoglou J.T., Larkın N.K., Kolden C.A., Stocks B., (2015), Climate Change Presents Increased Potential For Very Large Fires in the Contiguous United States, International Journal of Wildland Fire, 24, 892 - 899.

Bilgili E., Küçük Ö., (2001), Yanıcı Madde Durumunun Yangın Hassasiyet Sinıflarının Belirlenmesindeki Önemi, I Ulusal Ormanc1lık Kongresi, 19-20 Mart, Ankara.

Chen W., Moriya K., Sakai T., Koyama L., Cao C.X., (2016), Mapping a burned forest area from Landsat TM data by multiple methods, Geomatics, Natural Hazards and Risk, 7(1), 384- 402.

Chuvieco E., Aguado I., Jurdao S., Pettinari M.L., Yebra M., Salas J., Hantson S., De La Riva J., Ibarra P., Rodrigues M., Echeverria M., Azqueta D., Roman M.V., Bastarrika A., Martinez S., Recondo C., Zapico E., Martinez-Vega F.J., (2012), Integrating Geospatial Information into Fire Risk Assessment, International Journal of Wildland Fire, 23, 606 - 619.

Çekmek M., (2018), Vahşi Orman Yangınlarının Kanada Orman Yangın Hava İndeksi Yöntemi İle Analizi: Çanakkale Örneği, Yüksek lisans Tezi, Çanakkale Onsekiz Mart Üniversitesi, Sosyal Bilimler Enstitüsü, Coğrafya Anabilim Dalı, Çanakkale, Türkiye.

Doherty M.D., Lavorel S., CollOff M.J., Williams K.J., Williams R.J., (2017), Moving From Autonomous To Planned Adaptation in the Montane Forests Of Southeastern Australia Under Changing Fire Regimes, Austral Ecology, 42, 309-316. 
Dowdy A.J., Mills G.A., Finkele K., de Groot W., (2009), Australian Fire Weather As Represented by the Mcarthur Forest Fire Danger Index and the Canadian Forest Fire Weather Index, The Centre For Australian Weather and Climate Research, CAWCR Technical Report No: 10, Melbourne, Australia, 91ss.

Dragozi E., Gitas I.Z., Stavrakoudis D.G., Theocharis J.B., (2014), Burned area mapping using support vector machines and the FuzCo feature selection method on VHR IKONOS imagery, Remote Sensing, 6 (12), 12005-12036.

Esemen K., (2011), Forest Fires Analysis Using Satellite Imagery, Yüksek lisans tezi, İstanbul Teknik Üniversitesi, Bilişim Enstitüsü, İstanbul, Türkiye.

Göktepe S., Avcı M., (2015), Muğla-Fethiye Ormanlarında Yangın Sorunu, Yangınların Dağılımı ve Yangınlar Üzerinde Etkili Olan Faktörler, Turkish Journal of Forestry (Türkiye Ormancıllk Dergisi),16(2), 130-140.

Gülersoy A.E., (2014), Seferihisar'da Arazi Kullanımının Zamansal Değişimi (1984-2010) ve İdeal Arazi Kullanımı İçin Öneriler, SDÜ Fen Edebiyat Fakültesi, 31, 155-180.

Hacısalihoğlu M., (2018), Çok Kriterli Karar Analizi ile Orman Yangını Risk Haritalarının Oluşturulması: Karabük örneği, Yüksek lisans tezi, Zonguldak Bülent Ecevit Üniversitesi, Zonguldak, Türkiye.

Hatfield J. L., Kanemasu E. T., Asrar G., Jackson R. D., Pinter P.J. Jr., Reginato R. J., Id S.B., (1985), Leaf area estimates from spectral measurements over various planting dates of wheat, Int.J. Remote Sensing, 6(1), 67-75.

İnan Ç., (2018), Uydu Görüntü Verileri Kullanılarak Orman Yangın Analizi, Yüksek lisans tezi, İstanbul Teknik Üniversitesi, Bilişim Enstitüsü, İstanbul, Türkiye.

Kandemir E., (2010), Uzaktan Algılama Tekniğinde NDVI Değerleri ile Doğal Bitki Örtüsü Tür Dağılımı Arasındaki İlişkilerin Belirlenmesi Üzerine Araştırmalar, Yüksek Lisans Tezi, Ege Üniversitesi, İzmir.

Kane V.R., Cansler C.A., Povak N.A., Kane J.T., Mcgaughey R.J., Lutz J.A., Churchill D.J., North M.P., (2015), Mixed Severity Fire Effects Within the Rim Fire: Relative Importance of Local Climate, Fire Weather, Topography and Forest Structure, Forest Ecology and Management, 358, 62-79.

Kavzoglu T., Yildiz M., Tonbul H., (2016), Evaluating Performances of Spectral Indices for Burned Area Mapping Using ObjectBased Image Analysis, 12th International Symposium on Spatial Accuracy Assessment in Natural Resources and Environmental Sciences, 5 - 8, Montpellier, France.

Key C.H., Benson N.C., (2006), Landscape assessment (LA) sampling and analysis methods, USDA Forest Service, Rocky Mountain Research Station, General Technical Report RMRS-GTR-164-CD, 55ss.

Koutsias N., Karteris M., (2000), Burned area mapping using logistic regression modeling of a single post-fire Landsat-5 Thematic Mapper image, International Journal of Remote Sensing, 21(4), 673-687.

Küçük Ö., Ünal S., (2005), Yangın Hassasiyet Derecesinin Belirlenmesi: Taşköprü Orman İşletme Müdürlüğü Örneği, Kafkas Üniversitesi, Artvin Orman Fakültesi Dergisi, 6(1-2): 28-34.

Küçükosmanoğlu M.A., Ayberk H., Küçükosmanoğlu A., (2015), İstanbul Orman Bölge Müdürlü̆̈̈̈'nde Orman Yangınlarına Karşı Alınan Koruma ve Savaş Uygulamalarının İrdelenmesi, Journal of The Faculty of Forestry Istanbul University, 65(1), 41-52.

Lanorte A., Danese M., Lasaponara R., Murganate B., (2013), Multiscale Mapping of Burn Area and Severity Using Multisensor Satellite Data and Spatial Autocorrelation Analysis, International Journal of Applied Earth Observation and Geoinformation, 20, 42-51.

Li Z., Fraser R., Jin J., Abuelgasim A. A., Csiszar I., Gong P., Hao W., (2003), Evaluation of algorithms for fire detection and mapping across North America from satellite, Journal of Geophysical Research: Atmospheres, 108(D2):4076, 1-12.

Lopez S., Gonzalez F., Llop R., Cuavas J. M., (2007), An Evaluation of the Utility of NOAA AVHRR Images For Monitoring Forest Fire Risk in Spain. International Journal of Remote Sensing, 12, 1841 - 1851.

Miller J.D., Thode A.E., (2007), Quantifying Burn Severity in A Heterogeneous Landscape with A Relative Version of The Delta Normalized Burn Ratio (dNBR), Remote Sensing of Environment, 109, 66-80.

Molders N., (2010), Comparison Of Canadian Forest Fire Danger Rating System and National Fire Danger Rating System Fire Indices Derived From Weather Research and Forecasting (Wrf) Model Data For the June 2005 Interior Alaska Wildfires, Atmospheric Research, 95, 290 - 306.

Neary D.G., Klopatek C.C., Debano L.F., Folliott P.F., (1999), Fire effects on belowground sustainability: a review and synthesis, Forest Ecology and Management, 122(1-2): 51-71.

Özhatay N., Kültür Ş., (2006), Check-list of additional taxa to the Supplement Flora of Turkey III, Turkish Journal of Botany, 30(2006), 281-316.

Özhatay N., Kültür Ş., Aslan S., (2009), Check-list of additional taxa to the supplement Flora of Turkey IV, Turkish Journal of Botany, 33(2009), 191-226.

Özhatay F.N., Kültür Ş., Gürdal M.B., (2011), Check-list of additional taxa to the supplement Flora of Turkey V, Turkish Journal of Botany, 35(2011), 589-624.

Perry G.L.W., Wilmshurst J.M., Mcglone M.S., (2014), Ecology and Long-Term History of Fire in New Zealand, New Zealand Journal of Ecology, 38, 157- 176.

Robichaud P.R., (2000), Fire effects on infiltration rates after prescribed fire in northern Rocky Mountain forests, USA, Journal of Hydrology, 231-232: 220-229.

Rogan J., Franklin J., (2001), Mapping wildfire burn severity in southern California forests and shrublands using Enhanced Thematic Mapper imagery, Geocarto International, 16(4), 91-106.

Roy D.P., Boschetti L., Trigg S.N., (2006), Remote Sensing of Fire Severity: Assessing The Performance of The Normalized Burn Ratio, IEEE Geoscience and Remote Sensing Letters, 3, 112-116.

Rulli M.C., Rosso R., (2007), Hydrologic response of upland catchments to wildfires, Advances in Water Resources, 30: 20722086.

Sanjuan G., Brun C., Margalef T., Cortes A., (2014), Wind Field Uncertainty in Forest Fire Propagation Prediction. Procedia Computer Science, International Conference on Computational Science, 29, 1535 - 1545. 
Schelhaas M.J., Nabuurs G.J., Hengeveld G., Reyer C., Hanewinkel M., Zimmermann N. E., Cullmann D., (2015), Alternative Forest Management Strategies To Account For Climate Change-Induced Productivity and Species Suitability Changes in Europe, Regional Environmental Change, 15(8), 1581 - 1594.

Shijo J.S., Anitha K., Murthy M.S.R., (2009), Forest Fire in India: A Review of the Knowledge Base, Journal of Forest Research, 14:3, 127-134.

Tonbul H., (2015), Uydu Görüntü Verileri Kullanılarak Orman Yangın Şiddeti ve Yangın Sonrası Durumun Zamansal Olarak Incelenmesi: Akdeniz Bölgesi örneği, Yüksek lisans tezi, İstanbul Teknik Üniversitesi, İstanbul, Türkiye.

Tucker C., (1979), Red and photographic infrared linear combination for monitoring vegetation, Remote Sensing of Environment, 8 , $127-150$.

Türkeş M., Altan G., (2014), Türkiye'de 2011'de Oluşan Orman Yangınlarının Klimatolojik Çözümlemesi ve Hidroklimatik, Yüzey Hava ve Yüksek Atmosfer Koşulları ile Bağlantıları, International Journal of Human Sciences, 11(1), 145-176.

URL-1, (2018), https://www.ogm.gov.tr/ekutuphane/Yayinlar/T\%C3\%BCrkiye\%20Orman\%20Varl\%C4\%B1\%C4\%9F\%C4_B1.pdf, [Erişim 01 Ekim 2018].

URL-2, (2018), https://wildfiretoday.com/2010/03/14/wind-fuels-a-fire/fire_triangle/, [Erişim 24 Eylül 2018].

URL-3, (2018), http://web.archive.org/web/20160313143351/http://izmir.yerelnet.org.tr/, [Erişim 11 Kasım 2018].

URL-4, (2018), https://tr.climate-data.org/location/21649/, [Erişim 06 Temmuz 2018].

URL-5, (2018), https://landsat.usgs.gov/what-are-band-designations-landsat-satellites, [Erişim 24 Aralık 2018].

URL-6, (2018), https://www.ntv.com.tr/turkiye/seferihisarda-700-hektar-orman-kul-oldu,hEAxhL3oyEm0mnMbVqs1ww, [Erișim 22 Aralık 2018].

Veraverbeke S., Lermitte S., Verstraeten W.W., Goossens R., (2010), The temporal dimension of differenced Normalized Burn Ratio $(d N B R)$ fire/burn severity studies: The case of the large 2007 Peloponnese wildfires in Greece, Remote Sensing of Environment, 114(11), 2548-2563.

Vieira A., Bento Gonçalves A., Martins C., Leite F.F., Mendes L., (2011), Geographical Information Technology to Support Research on Forest Fires and Soil Erosion, 3rd International Meeting of Fire Effects on Soil Properties, University of Minho Guimarães, Portugal.

Y1ldız O., Esen D., Sargınc1 M., Toprak B., (2010), Effects of forest fire on soil nutrients in Turkish pine (Pinus brutia, Ten) Ecosystems, Journal of Environmental Biology, 31, 11-13. 